\title{
Demographic Situation in Eritrea
}

\section{GEBREMARIAM WOLDEMICAEL}

\author{
Doctoral Student \\ Demography Unit \\ Stockholm University \\ Stockholm, Sweden
}

\begin{abstract}
This paper gives estimates of the following demographic indicators for Eritrea: population size, annual growth rate, age and sex composition, fertility, infant, and child mortality. Brief background sections place the demographic characteristics in a broader perspective. The data used in the analysis of fertility and mortality are taken from sample surveys conducted after independence. Other figures are obtained from government and non-government reports. Indirect techniques were employed to analyze the fertility and mortality rates. Results indicate that the total population of Eritrea in 1993 was roughly 3.5 million. The average annual rate of population growth is found to be about $3 \%$. Children fourteen years old or younger are estimated to be about $46 \%$ of the total population. Only $4 \%$ of Eritreans are 65 years of age or older. The findings also reveal that fertility rates in Eritrea are high. Women have on average about 7.0 children. The findings further indicate an infant mortality of 112 and an under-five mortality of 208 deaths per 1,000 live births. Given the poor socioeconomic situation of the country, these rates, especially the infant mortality rate, are considered to be underestimates. Further research is therefore needed to ascertain the prevailing situation of Eritrea.
\end{abstract}

Keywords: history, population, society, health, fertility, infant mortality, child mortality, Eritrea

\section{Background to Eritrea}

\section{The physical setting}

Eritrea is situated in the Horn of Africa and covers about 120,000 square kilometers, about the size of Greece. It is bordered by Sudan on the north and west, the Red Sea on the east, Ethiopia on the south, and the Republic of Djibouti on the southeast. The country has impressive topography ranging from the central highland region of over 2,000 meters above sea level dropping to the Danakil depression, which lies about 100 meters below sea level where some of the highest temperatures on earth have been recorded.

Broadly speaking, Eritrea is divided into three physiographic regions: the central highlands, the western lowlands, and the eastern lowlands (also known as the coastal plains). These regions manifest distinct climatic and socioeconomic characteristics. The highlands, with an average elevation of about 2,000 meters above sea level, the most densely populated and highly utilized part of the country, enjoy a tropical highland 
climate. The western lowlands are to the west of the highlands and have an average elevation of about 1,000 meters. The eastern lowlands with an average elevation of about 500 meters (the Danakil depression is located here) are arid and semi-arid.

\section{Historical situation}

Located on an important sea route between Europe and Asia, Eritrea has suffered invasion, occupation, and plunder through much of its history. Because of its strategic significance, Eritrea attracted many expansionists and colonizers, among which are the Ottoman (16th century), the Egyptian (19th century), the Italian (1882-1941), the British (1942-1950), and the Ethiopian (1952-1990). Of these, the Italian occupation had a distinct impact on the formation and development of the nation's identity. It was during the Italian occupation that Eritreans, regardless of their ethnic, religious, and cultural histories, began to feel that they were one nation who belong to one land. Indeed, Eritrea's present boundaries were established by Italian administrators (Government of Eritrea 1993).

After the Italian rule in Eritrea came to an end in 1941, Eritrea was brought under British Military Administration. However, this did not improve the Eritrean political situation. In fact it was a period of increasing political turmoil and insecurity. More than a dozen political parties were born during this time. In 1950, the United Nations passed a resolution which formally federated Eritrea and Ethiopia. This resolution made Eritrea economically impotent and militarily defenseless. To this end, the executive and legislative branches of the Eritrean government were reduced and opponents to union with Ethiopia were dismissed and in some cases imprisoned, to be replaced with more unionists. Finally, in 1962, Ethiopia formally annexed Eritrea unilaterally and with that the internal self-administration of Eritrea came to an end. Eritrea's long armed struggle for independence began in 1961, even before Ethiopia annexed the state. As Ethiopia's oppressive administration reached further into the society, more and more Eritreans joined the liberation movement. This in turn led to more oppressive responses from Ethiopia, including mass arrests and the burning of entire villages. After thirty years of war, the Eritrean Peoples Liberation Front (EPLF) emerged victorious in the war for liberation on 24 May 1991. On April 1993, almost two years after the liberation of the country, a free and fair referendum of the people was held in the country. An overwhelming $98 \%$ of the voting population decided in favor of independence and a month later, on 24 May 1993, the independence of Eritrea was formally declared. Although it is difficult to enumerate all the impact of the war of independence in this paper, an attempt is made to name only a few in the following section.

\section{Impact of the war of independence}

In addition to the sufferings and mass arrests by the Ethiopian regime, key problems have arisen during the thirty years war of independence which have had a significant impact on socioeconomic and people's lives. Thirty years of war have destroyed Eritrea's infrastructure and crippled its economy. Roads and railways are not serviceable. Power stations do not function. Communication links are in serious disrepair. The few existing schools and health centers are grossly inadequate to meet growing needs.

The damage to individual lives has also been extensive. Tens of thousands of Eritreans died as a direct consequence of the fighting or an indirect consequence of col- 
lapsed health care and other services. As many as one million, fearing death, chose the flee, and many of this Eritrean diaspora have not returned home. According to the Commission for Eritrean Refugee Affairs (1993), at the war's end, about 700,000 refugees were living in Sudan and another 300,000 were living elsewhere, mostly in Ethiopia, Saudi Arabia, Europe, and the United States of America. There are also, according to a 1992 study conducted by the Office of Social Affairs, about 80,000 orphaned children in Eritrea, some 10,000 being the children of Eritrean combatants who had died in the war. Another 10,000 fighters were handicapped in the long struggle for independence. Another relevant feature is that about 60,000 of households became female-headed, probably because of the higher number of men killed or crippled in the war.

\section{Socioeconomic situation}

The Eritrean population is not culturally and linguistically homogeneous. Roughly, there are at least nine different cultures to be distinguished in the country, displaying differences in language, customs and dress. About $50 \%$ of Eritreans are Tigrigna, who are mostly farmers in the central highlands. About $31.4 \%$ are Tigre, who live mostly in the north and are engaged in animal husbandry and mixed farming. The other seven groups are much smaller: only the Saho and the Afar, mostly pastoralists who live in the eastern and southeastern part of the country reach $5 \%$ of the population. The Hedarib in the northwest are about $2.5 \%$ of the population, the Bilen in the northern part are about $2.1 \%$, the Kunama and the Nara in the west are about $2 \%$ and $1.5 \%$, respectively, and the Rashaida in the northeast are about $0.5 \%$ (Department of Geography 1992). Today the working languages are Tigrigna and Arabic, especially the former. English is also widely spoken.

Each ethnic group uniquely determines its own definition of sociocultural practices which results in many variations. Lifestyles range from desert-dwelling nomadic and pastoralist groups to agriculturists, and from deeply religious Eritrean Christians and Moslems to primitive pagans. One can also find differences between cultures involving teenage marriages, various marriage rites, social taboos, and distinctive civil laws.

Agriculture is the mainstay of the Eritrean economy. Over $80 \%$ of the population engages in agriculture. Unfortunately, productivity is very low. The agricultural sector, including livestock and fisheries, contributes only about one-quarter of the country's gross domestic product (GDP). Even in years of good rainfall Eritrea records a large food deficit (Government of Eritrea and UNICEF 1994).

\section{Education}

In its effort to achieve education for all, in 1991 the government made education compulsory for all children of primary school age. In addition, the government has taken measures to strengthen and expand the education infrastructure and to improve both the quantity and quality of teaching. Despite of all these efforts the enrollment and female participation rates are still low. At present only about $26 \%$ of primary school age children (7-11 years of age) are enrolled in school. The Ministry of Education (1993) has identified many factors contributing to low enrollment and a high drop-out rate as well as repetition in Eritrea. These include socioeconomic problems, parents' 
negative perceptions about the usefulness of education, lack of properly trained teachers, an inadequate supply of textbooks, and other learning materials and long distances to schools.

In addition to the above, low female enrollment can be explained by the following factors: The demand for a girl's labor (e.g. to cook, collect water and firewood, or care for younger children) may be greater than the demand for a boy's labor. Traditional religious and cultural expectations may be an impediment: Women and girls may be confined to the home, girls may be expected to marry and have children from a very young age (under 15). Unaccompanied travel over long distances to schools, particularly in rural areas, may also be an impediment.

\section{Health problems}

Eritrea has endorsed the objective of health for all by the year 2000 using the primary health care strategy as its mode of implementation. However, the health care service has always been limited in scope, and economic decline has critically curtailed the government's ability to adequately provide or significantly improve health services. Promotive and preventive care such as immunization, health education, and the control of infectious diseases were relatively neglected until the independence. During Eritrea's war of independence, this hospital-based health care network was almost completely destroyed. Buildings were ruined, doctors and nurses abandoned their posts, and international health care initiatives such as child immunization (though having enormous impact in other parts of Africa) were almost non-existent in Eritrea.

Recent reports from the Ministry of Health (1993) indicate that there are 13 functioning hospitals, 33 health centers, and 113 health stations. Moreover, about $40 \%$ of this system is below standard, without needed staff or supplies. At present, there is one doctor for every 33,000 people, but about half of them are in Asmara, leaving the rural areas badly underserved. Because transport and communication in the provinces are very poor, the health facilities in most rural Eritrea are isolated and effectively independent. Referrals from lower to higher level facilities are possible only in theory. It has been estimated that $54 \%$ of Eritreans live more than 20 kilometers from the nearest health station (Government of Eritrea and UNICEF 1994). In a rugged and mountainous terrain, even 10 kilometers may be too great a distance to travel, involving large costs (in transport, or in time lost from productive activities). A parent will not make this difficult and time-consuming journey until a child is very ill and perhaps beyond treatment.

Harmful traditional practices are still common in Eritrea. Many involve wounding the child. The majority of Eritrea's girls continue to be circumcised or infibulated. This practice, to which many Eritrean girls are subjected at a young age, contributes to the incidence of obstructed labor and hemorrhage during delivery. Although this traditional practice has no religious basis, virtually all women experience it with all the consequences for their own health immediately after circumcision and during pregnancy and delivery, and for the health of their infants. Other common traditional practice include cutting above the child's eyebrows to release swelling when a child has an infection, scarifying cheeks and the forehead, or rupturing the child's tonsils, and cutting the uvula and the eyelids. These traditional practices are performed by traditional healers. Moreover, there is ample and documented evidence that traditional healers and circumcisers do not use hygienic precautions, suggesting that these procedures often include a high risk of infection as well as a high risk of excessive blood loss, which can be lifethreatening (Selassie et al. 1985). 


\section{Sources of demographic data in Eritrea}

As a consequence of Eritrea's history as a colony, basic social, economic, and demographic data are scarce. Some surveys have been conducted, but these cover only a small geographical area or a small section of the population. There has been no survey or census of national scope which is reliable. Hence it is difficult to provide meaningful national figures of key demographic or socioeconomic indicators. Disaggregated figures by provinces are particularly difficulty to provide.

Various main data sources were used for the present paper, including previous reports and publications of government ministries and non-government organizations. The fertility and mortality data provided here comes from a Health and Nutrition Survey (HNS) and Fertility and Family Planning Survey (FFPS) conducted after independence. The HNS was a stratified cluster sample survey conducted by the Institute of Research and Development at the University of Asmara and UNICEF in 1993. This survey focused on indicators of children's and women's health and nutritional status. Although it was less comprehensive than a national demographic and socioeconomic survey, it is considered to give a general picture of the situation of children and women in Eritrea. The FFPS, on the other hand, was a two-stage sampling procedure and covers only Asmara, the capital city of Eritrea. The purpose of this survey was to collect data on fertility and contraceptive use among Asmara women.

\section{Population size and growth rate}

There is no reliable estimate of the population presently residing in Eritrea, and the number of Eritreans living abroad, many of whom are potential returnees, is equally uncertain. However, some estimates of the total population are given by different sources. The Ethiopian Central Statistical Authority has extrapolated (using an annual population growth of $2.9 \%$ ) the population of Eritrea at 3.5 million in 1992. This translates into a 1993 population size of 3.65 million. The Ministry of Health estimated 3.25 million Eritreans in 1991, which is equivalent to 3.44 million in 1993 . The basis of this estimate is unknown. The University of Leed's Needs Assessment Study (1992) also calculated a total 1991 population of 3.09 million, equivalent to 3.27 million in 1993. This survey appears to be the only one with an independent empirical basis. It is based on a survey of 401 villages (out of 2,546 said to exist).

Since different sources give different figures, it appears that there is no single estimate of the population of Eritrea today. It seems reasonable therefore that a range rather than a single numerical figure would be more appropriate in this case. Thus, it may be said that the population size of Eritrea as of 1993 was between 3.3 and 3.6 million.

As there is no reliable information about population size, the population growth rate is not known with precision. The study conducted by the University of Leeds however, estimated the average annual rate of growth of Eritrea's population to be about $3 \%$ for the period 1984 to 1991 . To the extent that this rate reflected the reality of the past, it may be higher at present, because baby booms are fairly common occurrences in postwar years.

\section{Age and sex composition}

Data which disaggregate Eritrea's population according to sex and broad age groups is available, though based on projections (see Table 1). As can be seen from Table 1, 
the age distribution is typical of high fertility regimes in which a larger proportion of the population is to be found in the younger age groups than in the older age groups. For 1990 , children fourteen years old or younger were estimated to be about $46 \%$ of the total population. Only $4 \%$ of Eritreans were 65 years of age or older. The remaining $50 \%$ of the population fell in the 15-64-year-old group. One in five is a child under five years of age.

$\mathrm{T}$ a b le 1. Eritrea's population by age group and sex (percent).

$\begin{array}{lrrr}\text { Age group } & \text { Male } & \text { Female } & \text { Total } \\ 0-4 & 8.9 & 8.7 & 17.6 \\ 5-14 & 14.5 & 13.9 & 28.4 \\ 15-44 & 18.6 & 20.4 & 39.0 \\ 45-64 & 5.7 & 5.5 & 10.9 \\ 65+ & 2.2 & 1.8 & 4.0 \\ \text { all ages } & 49.9 & 50.0 & 99.9\end{array}$

Source: projected from data in the statistical bulletin for the administrative region of Eritrea, Government of Ethiopia, 1989.

\section{Fertility and childhood mortality}

\section{Fertility data}

During the war of independence, no reliable fertility data were collected in Eritrea. Surveys conducted after independence (although not comprehensive) give some estimates of fertility. Among these are the HNS survey which roughly covers the whole country and the FFPS survey which covers only Asmara. Asmara contains more than half of the urban population and has cultural and demographic characteristics similar to other urban areas in Eritrea. It appears reasonable therefore to consider tentatively the FFPS data as representative for urban Eritrea as a whole. Moreover, $80 \%$ of Eritrea's population are rural residents, and therefore the HNS data reflect the rural population more than the urban population. Two kinds of fertility data are tabulated from the above surveys: mean number of children ever born (MNCEB) and age-specific fertility rates (ASFR).

\section{Mean number of children ever born}

Estimates of the MNCEB from the HNS survey are presented in Table 2 along with those estimated from the FFPS survey. True to expectation, in both surveys, the MNCEB increases steadily with the age of women. The HNS data, however, reveal higher MNCEB for each age group than those for the FFPS data. This suggests difference in fertility between the country as a whole (which is $80 \%$ rural) and the urban areas. Such difference in the MNCEB probably reflects lifecycle effects of rural-urban differences. Although urban fertility is lower than rural, the former is still high by any standard. Nevertheless, it appears that urbanization is beginning to have some impact on fertility levels in urban Eritrea (particularly in Asmara), though very little.

\section{Age-specific and total fertility rate}

Table 3 gives the reported and adjusted age-specific and total fertility rates for the urban areas. The age pattern of fertility indicates that women in urban Eritrea have 
$\mathrm{T}$ a b l e 2. Mean number of children ever born.

$\begin{array}{lcc}\text { Age group } & \text { HNS (country) } & \text { FFPS(urban) } \\ 15-19 & 1.40 & 0.89 \\ 20-24 & 1.95 & 1.86 \\ 25-29 & 3.25 & 2.64 \\ 30-34 & 4.69 & 4.17 \\ 35-39 & 5.66 & 5.17 \\ 40-44 & 6.83 & 5.50 \\ 45-49 & 7.60 & 6.16\end{array}$

$\mathrm{T}$ a b l e 3. Reported and adjusted age-specific and total fertility rates.

$\begin{array}{lcc}\text { Age group } & \text { Reported } & \text { Adjusted } \\ 15-19 & 0.122 & 0.128 \\ 20-24 & 0.286 & 0.300 \\ 25-29 & 0.296 & 0.310 \\ 30-34 & 0.283 & 0.297 \\ 35-39 & 0.239 & 0.250 \\ 40-44 & 0.087 & 0.091 \\ 45-49 & 0.020 & 0.021 \\ \text { TFR } & 6.67 & 6.99\end{array}$

children early in the childbearing period. By age 30, an Eritrean woman will have given birth to over one-half of the children she will ever have. From Table 3, it can also be seen that the fertility pattern conforms to the broad-peak type in which the maximum fertility occurs in the 20-29 year age group, and what is evident with the pattern is that fertility is relatively high at the extreme ages of childbearing, 15-19 and 44-49, particularly at the former.

The sum of the age-specific fertility rates (known as the total fertility rate, TFR) is a useful means of summarizing the level of fertility. It can be interpreted as the number of children a woman would have by the end of her childbearing years, if she were to pass through those years bearing children at the currently observed rates (United Nations 1983). In addition to the direct estimation of the TFR, we have also obtained an adjusted TFR using some indirect techniques, originally developed by Brass (1968; 1975 ) and subsequently modified by others (United Nations 1983).

Brass $(1968 ; 1975)$ has shown that the reported average number of children is frequently a downward-based estimate of the cumulative fertility experience of women over 35 years old (mainly due to problems of recall lapse). On the other hand, women under 35 years are assumed to report the number of children they have with much better accuracy. This is because these women do not have to recall events from the remote past or to count a large number of children. If we accept this assumption (that we can expect better accuracy in reporting children born to younger women) the $\mathrm{P}(\mathrm{i}) / \mathrm{F}(\mathrm{i}) \mathrm{ra}$ tio to women under 35 years old may be used as a correction factor. The adjustment factor used here is the average of $\mathrm{P}(2) / \mathrm{F}(2), \mathrm{P}(3) / \mathrm{F}(3)$, and $\mathrm{P}(4) / \mathrm{F}(4)$ (where $\mathrm{P}(\mathrm{i})$ and $\mathrm{F}$ (i) stand for parity and parity equivalent respectively for the age groups 20-24, 2529 , and 30-34). An examination of the two TFR estimates derived from the reported and adjusted ASFRs suggests a TFR of about 7.0 for urban Eritrea. This high TFR is not surprising in a country where marriage is early and contraceptive use is not common. 


\section{Infant and child mortality}

A first step towards acting to improve the well-being of children in Eritrea is assessing their present health situation, both to identify problems which require the most urgent response and to provide a baseline against which improvements can be measured. Infant and child mortality rates are key indicators of social welfare and they are also relatively simple to obtain. These rates are crucial for guiding the evaluation of the health system and for making public health policy at local levels.

In the absence of more detailed data, the information collected from the HNS survey is still the best available for estimating the level of infant and child mortality in Eritrea. In this paper, infant and child mortality will be measured using three rates. All the rates presented are probabilities of dying between two exact ages. These are:

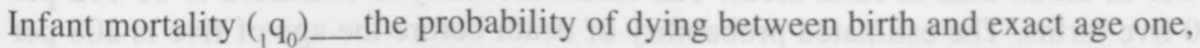
Under-five mortality $\left({ }_{5} q_{0}\right)_{-}$the probability of dying between birth and exact age five, and

Child mortality $\left({ }_{4} q_{1}\right)$ _t the probability of dying between exact ages one and five.

Indirect techniques of estimating infant and child mortality from children ever born and children surviving have made useful infant and child mortality measures available in many developing countries, despite the absence of dependable vital registration systems. Perhaps the most widely used of these indirect techniques is the one devised by Brass (1968) and later modified and improved by others (see United Nations 1983). The later version is used in estimating the infant and child mortality rates in this paper.

The estimated rates indicate an infant mortality and under-five mortality of 112 and 208 deaths per 1,000 live births respectively, suggesting that one child in ten dies before his/her first birthday and that two children in ten die before reaching the age of five. Child mortality is also estimated to be 108 per 1000 live births. This means that one child in ten that survives his/her first year dies before reaching the age of five. Although these rates are high by developed country's standards (e.g. in Sweden infant mortality rate is 4.8 per 1,000 live births ) (Statistics Sweden 1994), they are low compared to some other Sub-Saharan African countries. For example, infant mortality is about 144 in Liberia and under-five mortality is 247 in Mali (Sullivan et al. 1994). Given the poor socioeconomic situation of Eritrea, infant and child mortality, particularly the former, appear to be underestimates.

In a country without a traditional regular data source, it is difficult to establish the levels of infant and under-five mortality. Errors in the infant mortality rate are especially likely. In Eritrea, deaths are not commonly reported, so mortality data must be reconstructed from people's memories, through interviewers or questionnaires. In such cases, faulty memories are more likely to cause greater distortion in the infant mortality data than in the under-five mortality data, because infant mortality is more sensitive to boundary questions. For instance, a mother may remember that a child died around the twelfth month of its life, but she may be uncertain about whether the death occurred before or after the crucial boundary date. In addition, social and cultural norms may lead to undercounting: for instance, a baby who survives only a few hours or a few days after birth may not have been considered a live birth at all. Although this type of confusion would have an impact on both under-five and infant mortality rates, the impact on the infant mortality rate would be proportionately greater. Hence, the under-five mortality rate is more reliable than the infant mortality rate. It is therefore very likely that the low level of infant mortality found using the HNS survey may have some causal connection which could possibly have a cultural or social origin. 


\section{Conclusion}

In this paper an attempt has been made to present some information on population size, growth rate, age and sex composition, fertility and childhood mortality. In 1993, the total population of Eritrea was estimated to be 3.5 million (on the average), of which about $80 \%$ live in rural areas. The annual population growth rate is estimated at $3 \%$. The age and sex distribution of the population corresponds to the usual pattern of population pyramids in developing countries, where the population aged fourteen and younger is $46 \%$ while those aged 65 and over compose only $4 \%$.

The findings indicate that fertility in Eritrea is high by any standard. The completed fertility for the country estimated at about 7.0 children per woman, is even high by the Sub-Saharan Africa standards. Rural-urban comparison indicates that fertility is lower in urban than in rural areas. The infant mortality is estimated to be 112 per 1,000 live births. The estimated probability of death before the age of five is 208 per 1,000 live births. These figures appear to be underestimates, given the poor condition of health services and household conditions as well as the huge impact of the war of independence during the last three decades.

Finally, it is worth mentioning that as a result of the country's long liberation struggle, there are large gaps in demographic data from population censuses or surveys. In the absence of relevant data, the magnitude of the problems in health, education and other services of the population is not assessed. The need for a census or a survey would seem to be of the utmost urgency and should be undertaken, as early as possible. In addition, the author wishes to suggest that more research be done in the following areas in order to fill some of the gaps in demographic information:

1. Investigation on the levels, trends and differentials of fertility and early childhood mortality using sufficiently large sample data which disaggregate Eritrea's population according to province, rural-urban, sex and other socioeconomic categories, and

2. Research on the influence of harmful traditional practices, such as female excision and infibulation, early marriage, rupturing the child's tonsil, cutting the uvula, etc., on child and maternal mortality.

\section{Acknowledgments}

The writer gratefully acknowledges the useful suggestions and comments of Dr. Gigi Santow. The writer is solely responsible for the views expressed in this paper.

\section{References}

Brass, William. 1968. The Demography of Tropical Africa. Princeton: Princeton University Press.

-. 1975. Methods for estimating fertility and mortality from limited and defective data. An occasional publication.

Commission for Eritrean Refugee Affairs. 1993. The Cause of Exile and the Right of Return. Working paper.

Department of Geography at the University of Asmara. 1993. Department working paper.

Government of Eritrea. 1993. Birth of a Nation.

The Government of Eritrea and UNICEF. 1994. Children and Women in Eritrea.

Ministry of Education. 1993. Basic Information on Education. Working paper.

Ministry of Health. 1993. Working paper.

Selassie, Alasebu G., Mulumebet Desta and Zenebech Negash. 1985. Harmful Traditional Practices Affecting the Health of Women and Children in Ethiopia. Addis Ababa. 
Statistics Sweden. 1994. Statistical Yearbook of Sweden. Stockholm: Statistics Sweden.

Sullivan, Jeremiah M., Shea Oscar Rutstein and George T. Bicego. 1994. Infant and Child Mortality. Demographic and Health Survey. Comparative Studies No.15. Calverton, MD: Macro International, Inc.

United Nations. 1983. Manual X. Indirect Techniques for Demographic Estimation. New York: United Nations.

University of Leeds. 1992. Eritrea 1991. A Needs Assessment Study: Final report. An Independent Evaluation of the Food Situation in Eritrea in 1991. Leeds: University of Leeds. 